\title{
AVALIAÇÃO DA INGESTÃO DE VITAMINA D E CÁLCIO EM INDIVÍDUOS PRÉ-DIABÉTICOS E SUA RELAÇÃO COM A ESTABILIDADE GENÔMICA
}

\section{Caroline dos Santos}

Universidade de Santa Cruz do Sul (UNISC), Brasil.

\section{Patrícia Molz}

Doutoranda do Programa de Pós-Graduação em Medicina e Ciências da Saúde da Pontifícia Universidade Católica do Rio Grande do Sul (PUCRS), Brasil.

Camila Schreiner Pereira

Mestre em Promoção da Saúde pela Universidade de Santa Cruz do Sul (UNISC). Universidade de Santa Cruz do Sul (UNISC), Brasil.

\section{Silvia Isabel Rech Franke}

Bolsista de Produtividade em Pesquisa do CNPq. Coordenadora do Programa de Pós-Graduação em Promoção da Saúde (Mestrado) da Universidade de Santa Cruz do Sul (UNISC), Brasil.
Autor correspondente:

Patrícia Molz

patricia.molz@gmail.com
RESUMO: Avaliar a ingestão de vitamina D e cálcio em indivíduos pré-diabéticos e verificar sua relação com a estabilidade genômica. Estudo transversal, com 51 indivíduos pré-diabéticos. A ingestão de vitamina D e cálcio foi determinada no programa DietWin ${ }^{\circledR}$ e a avaliação da prevalência de inadequação dos nutrientes foi classificada de acordo com as recomendações das Dietary Reference Intakes (DRIs). O ensaio de citoma de micronúcleos com bloqueio de citocinese (CBMN) e o ensaio cometa foram utilizados para avaliar a estabilidade genômica. A prevalência de inadequação de vitamina D e cálcio foi de $94,1 \%$ e $86,3 \%$, respectivamente. $\mathrm{O}$ consumo de vitamina $\mathrm{D}$ associou-se à ingestão de cálcio $(r=0,66$ e $p<0,01)$ e ambos os micronutrientes se associaram com glicose de jejum $(\mathrm{p}<0,05)$. Em relação ao ensaio CBMN, o consumo de cálcio associou-se negativamente com a frequência de brotos nucleares $(r=-0,30$ e $p=0,04)$. Dentre os pré-diabéticos avaliados existe alta prevalência de inadequação de vitamina $\mathrm{D}$ e cálcio. Além disso, ambos os nutrientes pouco influenciaram na instabilidade genômica, pois apenas o consumo insuficiente de cálcio mostrou estar relacionado com danos no DNA, aumentando a formação de brotos nucleares.

PALAVRAS-CHAVE: Vitamina D; Cálcio; Estado pré-diabético; Dano ao DNA.

\section{THE INGESTION OF VITAMINS D AND CALCIUM IN PRE-DIABETIC PEOPLE AND ITS RELATIONSHIP WITH GENOMIC STABILIT Y}

\begin{abstract}
The ingestion of vitamins D and calcium in pre-diabetic people and its relationship with genomic stability are analyzed by a transversal study with 51 pre-diabetic people. The ingestion of vitamins D and calcium was determined in the DietWin ${ }^{\circledR}$ program and the evaluation of the prevalence of nutrient inadequacy was classified according to recommendations by Dietary Reference Intakes (DRIs). Assay on micronucleus cytome with cytokinesis blockage (CBMN) and comet assay evaluated genomic stability. Inadequacy prevalence of vitamins $\mathrm{D}$ and calcium was $94.1 \%$ and $86.3 \%$, respectively. The intake of vitamin $\mathrm{D}$ is associated with the ingestion of calcium $(\mathrm{r}=0.66$; $\mathrm{p}<0.01)$ and the two micronutrients are associated with fasting glucose $(p<0.05)$. In the case of CBMN, intake of calcium was associated negatively with the frequency of nuclear buds $(r=-0.30 ; p=0.04)$. There is high inadequacy prevalence for vitamins $\mathrm{D}$ and calcium among pre-diabetic people. The two nutrients only slightly affect genomic instability since only the insufficient intake of calcium proved to be related with DNA damage, increasing the formation of nuclear buds.
\end{abstract}

KEY WORDS: Vitamin D; Calcium; Prediabetic state; DNA damage. 


\section{INTRODUÇÃO}

A American Diabetes Association (ADA) define o termo pré-diabetes (PD) como sendo uma alteração na glicemia, não suficiente para ser diagnosticada como diabetes $^{1}$. Dentre os principais fatores de risco para o PD estão uma dieta inadequada, com ingestão excessiva de calorias e deficiência de micronutrientes ${ }^{2}$, obesidade (especialmente obesidade abdominal ou visceral), dislipidemia e hipertensão arterial ${ }^{3}$.

Alguns nutrientes, como vitamina D e cálcio, têm se mostrado benéficos na prevenção da hiperglicemia crônica ${ }^{4}$. A vitamina $\mathrm{D}$, encontrada em alimentos como peixes gordos e alimentos fortificados, bem como sintetizada pela exposição ao sol' , está relacionada com metabolismo da glicose por meio de mecanismos específicos $^{6}$. Níveis baixos de vitamina D sanguíneos podem levar à diminuição da função das células $\beta$, promovendo a resistência à insulina e intolerância à glicose e, consequentemente, levar ao desenvolvimento do diabetes mellitus tipo 2 (DM2) ${ }^{7}$. Por outro lado, o cálcio, um mineral presente em alimentos lácteos, tais como iogurte, leite e queijo ${ }^{8}$, tem demonstrado ser essencial para a resposta insulínica, uma vez que qualquer alteração nas suas concentrações pode levar à resistência a ação da insulina e, consequentemente, ao desenvolvimento do DM29.

O PD também tem sido associado ao aumento de danos oxidativos ${ }^{10,11}$, sendo a dieta, um fator crucial que pode influenciar na estabilidade genômica, uma vez que o desequilíbrio no consumo de nutrientes pode elevar as taxas de mutação no $\mathrm{DNA}^{12}$. Com isso, as deficiências de cálcio e vitamina $\mathrm{D}$ associadas ao PD podem produzir efeitos negativos na estabilidade genômica. Shea e Gradinaru ${ }^{13}$ encontraram uma relação inversa entre marcadores de danos oxidativos e vitamina D, enquanto que Ferraz, Steluti e Marchioni ${ }^{14}$ mostraram que o aumento nas concentrações de cálcio pode gerar o dano oxidativo por meio de mediadores de apoptose, induzidos por compostos de vitamina $\mathrm{D}$, e, além disso, enfatizaram que o cálcio participa na regulação da proliferação e diferenciação celular.

Em vista disso, o objetivo do presente estudo foi avaliar o consumo de vitamina D e cálcio e associá-los com a estabilidade genômica em indivíduos pré-diabéticos.

\section{METODOLOGIA}

A presente pesquisa trata-se de um estudo transversal-quantitativo descritivo, com amostra não aleatória, aprovado pelo Comitê de Ética em Pesquisa da Universidade de Santa Cruz do Sul (UNISC), sob o parecer $n^{\circ} 2687 / 10$.

A amostra foi composta por 51 indivíduos prédiabéticos, de ambos os sexos, com idade entre 20 a 60 anos, que aceitaram participar do estudo e que consultaram nas Unidades Básicas de Saúde (UBS) de Santa Cruz do Sul e no Serviço Integrado de Saúde (SIS) da Universidade de Santa Cruz do Sul (UNISC), mediante a assinatura do Termo de Consentimento Livre e Esclarecido (TCLE).

Para o rastreamento do PD foram utilizados dois critérios propostos pela $\mathrm{ADA}^{1}$ para diagnóstico de prédiabetes: níveis de glicemia de jejum entre $100-125 \mathrm{mg}$ / dL ou hemoglobina glicada (A1C) entre 5,7-6,4\%.

O consumo de vitamina $\mathrm{D}$ e cálcio na dieta foi avaliada em dias alternados, a partir de um recordatório alimentar de 24 h (R24h) e dois registros diários (RD), de acordo com Fisberg et al..$^{15}$ que posteriormente foi digitado e analisado no programa DietWin ${ }^{\circledR}$. Analisouse a distribuição de consumo dos micronutrientes em relação às calorias consumidas e, a partir dos valores de referência dos critérios da Dietary Reference Intakes (DRIs), avaliou-se a inadequação da ingestão de vitamina D e cálcio na dieta utilizando a Estimated Average Requirement (EAR) ${ }^{8}$.

Para avaliar a estabilidade genômica realizou uma coleta de sangue, por um profissional habilitado, bem como se realizou a coleta de células da mucosa bucal. O sangue coletado foi utilizado para avaliação de danos no DNA pelo ensaio cometa alcalino e células da mucosa oral para o ensaio de citoma de micronúcleo com bloqueio de citocinese (CBMN).

$O$ ensaio cometa $^{16}$ foi realizado segundo protocolo padrão do grupo de pesquisa, no qual células sanguíneas $(5 \mu \mathrm{L})$ foram misturadas a $95 \mu \mathrm{L}$ de agarose de baixo ponto de fusão (LMP) (0,75\%). A mistura (células e agarose) foi acrescentada às lâminas précobertas com agarose normal (NMP) (1,5\%) e cobertas com lamínulas. Após a solidificação (cerca de 10 minutos a $4^{\circ} \mathrm{C}$ ), as lamínulas foram removidas e as lâminas foram colocadas em solução de lise gelada $(2,5 \mathrm{M} \mathrm{NaCl}, 100 \mathrm{mM}$ EDTA e 10 mM Tris, pH 10,00 - 10,50, e acrescida de 1\% 
Triton X-100 e 10\% DMSO) por um período mínimo de 1 hora. Subsequentemente, as lâminas foram dispostas em cuba de eletroforese e mantidas imersas por 20 min a $4^{\circ} \mathrm{C}$ em solução de eletroforese alcalina $(300 \mathrm{mM}$ $\mathrm{NaOH}, 1 \mathrm{mM}$ Na2EDTA, $\mathrm{pH}>13$ ), para desnaturar o DNA. Decorridos os 20 minutos, foi realizada a eletroforese por $15 \mathrm{~min}\left(4^{\circ} \mathrm{C}\right)$ a $300 \mathrm{~mA}$ e $25 \mathrm{~V}(0,90 \mathrm{~V} / \mathrm{cm})$. Depois da eletroforese, as lâminas foram neutralizadas $(0,4 \mathrm{M}$ Tris, $\mathrm{pH} 7,5)$, fixadas e coradas com nitrato de prata.

Foram avaliadas 100 células por indivíduo/ amostra, selecionadas aleatoriamente 50 células por lâmina, (2 lâminas por indivíduo), em microscópio convencional com magnificação de 200X. O dano foi visualmente determinado pela classificação de cometas em cinco classes de migração de DNA, de dano 0 (nenhuma cauda) até dano 4 (dano máximo, comprimento total do início da cabeça ao final da cauda). O índice de dano (ID) foi obtido pela soma de células individuais classificadas, variando de 0 (nenhum dano: 100 células $\mathrm{x} 0$ ) para 400 (dano de máximo: 100 células $x$ 4). A Frequência de Dano (FD), em porcentagem (\%), foi calculada pela relação entre o número de células com dano (classificadas de 1 a 4) e o total de células da amostra. Células com núcleos não detectáveis (NDCN) (cabeça e cauda separadas) não foram consideradas.

Para avaliação do CBMN, adaptado de Fenech ${ }^{17}$, amostras de sangue foram colocadas em cultura contendo RPMI, soro bovino fetal e fito-hematoglutinina. Após os frascos serem incubados em estufa a $37^{\circ} \mathrm{C}$ por 44 horas, adicionou-se citocalasina $\mathrm{B}$ e, por conseguinte, as células foram incubadas por mais 28 horas. Subsequentemente, as suspensões celulares foram tratadas com agente hipotônico (KCl), fixadas e, então, pingadas sobre lâminas de microscopia (2 lâminas por indivíduo). As lâminas foram coradas com Giemsa e analisadas 1.000 células por indivíduo. As células binucleadas (BNC; 1000 células) foram analisadas quanto à presença de micronúcleos (MN) - biomarcadores de quebra ou perda de cromossomos -, brotos nucleares - buds (NBUD) - biomarcador de eliminação de DNA amplificado e/ou complexos de reparação de DNA - pontes nucleoplasmáticas (NPB) biomarcador de rearranjo cromossômico, má reparação e/ ou fusão de telômeros e a soma dos tipos de danos (N.A). As células mononucleadas, binucleadas, multinucleadas, apoptóticas e necróticas foram determinadas pela análise de 1.000 células.

O programa GraphPad Prisma versão 6.01 foi utilizado para a análise dos dados e para a construção dos gráficos. Uma análise descritiva da amostra foi realizada, no qual as variáveis contínuas foram descritas por meio de medidas de tendência central (médias) e de dispersão (desvio-padrão ou percentis) e as variáveis qualitativas, em número e percentual, conforme a distribuição dos dados. Todas as variáveis quantitativas foram testadas para homocedasticidade (teste de Bartlet) e normalidade (teste de Kolmogorov Smirnov). O intervalo de confiança (IC95\%) e amplitude foi calculado para a prevalência de inadequação de vitamina $\mathrm{D}$ e cálcio. As variáveis referentes ao consumo de vitamina $\mathrm{D}$ e cálcio foram associadas às de estabilidade genômica utilizando-se a análise de correlação (Pearson ou Spearman), bem como se calculando também o $\mathrm{R}^{2}$ e o tamanho do efeito das correlações conforme Hopkins et al. ${ }^{18}$. O nível de significância utilizado foi de $\mathrm{p}<0,05$.

\section{RESULTADOS}

As características clínicas dos indivíduos deste estudo estão descritas na Tabela 1. A amostra foi constituída por 51 indivíduos, sendo a maioria do sexo feminino $(66,7 \%)$.

A prevalência de inadequação do consumo de vitamina D e cálcio está apresentada na Tabela 2 , conforme as recomendações das DRIs ${ }^{8}$. O consumo médio diário de vitamina $\mathrm{D}$ foi de 3,38 $\pm 4,98 \mu \mathrm{g} / \mathrm{dia}$, sendo a prevalência de inadequação de $94,1 \%$. O cálcio apresentou ingestão média diária de $548,55 \pm 278,02 \mathrm{mg} /$ dia com prevalência de inadequação de $86,3 \%$.

Observou-se associação forte e de forma significativa entre o consumo de vitamina $D$ e cálcio $(r=0,66$ e $\mathrm{p}<0,01$ ), conforme a Figura 1. Além disso, a ingestão de ambos os nutrientes se correlacionou fracamente, mas significativamente com a glicose de jejum (vitamina D $v$ glicose: $\mathrm{r}=0,29$ e $\mathrm{p}=0,05$; cálcio $v$ glicose: $\mathrm{r}=0,30$ e $p=0,03)$. Diferentemente, a hemoglobina glicada não se correlacionou com a ingestão de vitamina $\mathrm{D}(\mathrm{r}=0,04$ e $\mathrm{p}=0,79)$, nem com o consumo de cálcio $(\mathrm{r}=0,05$ e $\mathrm{p}=0,75)$ (Figura 2). 
Tabela 1. Caracterização clínica dos indivíduos pré-diabéticos $(n=51)$. Santa Cruz do Sul, 2012

\begin{tabular}{|c|c|c|}
\hline Variável & Média $\pm D P$ & $\begin{array}{c}\text { Frequência } \\
\%(n)\end{array}$ \\
\hline Idade média (anos) & $50,78 \pm 9,25$ & \\
\hline \multicolumn{3}{|l|}{ Sexo } \\
\hline Feminino & & $66,7 \%(34)$ \\
\hline Masculino & & $33,3 \%(17)$ \\
\hline Glicose de jejum (mg/dL) & $96,16 \pm 13,01$ & \\
\hline A1C (\%) & $6,14 \pm 0,32$ & \\
\hline Índice de massa corporal $\left(\mathrm{kg} / \mathrm{m}^{2}\right)$ & $30,32 \pm 4,80$ & \\
\hline \multicolumn{3}{|l|}{ Classificação do estado nutricional $^{\text {a }}$} \\
\hline Eutrofia & & $17,6 \%(9)$ \\
\hline Sobrepeso & & $25,5 \%(13)$ \\
\hline Obesidade & & $56,9 \%(29)$ \\
\hline \multicolumn{3}{|l|}{ Classificação da gordura corporal $(\%)^{b}$} \\
\hline Adequado & & $9,8 \%(5)$ \\
\hline Excesso & & $17,6 \%(9)$ \\
\hline Obesidade & & $72,5 \%(37)$ \\
\hline Relação cintura-quadril (au) & $0,88 \pm 0,09$ & \\
\hline Adequado & & $47,1 \%(24)$ \\
\hline Alto risco de doença cardiovascular & & $52,9 \%(27)$ \\
\hline \multicolumn{3}{|l|}{ Circunferência da cintura $(\mathrm{cm})$} \\
\hline Adequado & & $19,6 \%(10)$ \\
\hline Alto risco de doença cardiovascular & & $80,4 \%(41)$ \\
\hline
\end{tabular}

aClassificação do estado nutricional de acordo com a Organização Mundial as Saúde (1995)

bestimativa do percentual de gordura segundo Pollock e Wilmore (1993).

Fonte: Dados da pesquisa

Tabela 2. Prevalência de inadequação do consumo de vitamina D e cálcio de indivíduos pré-diabéticos $(\mathrm{n}=51)$ de acordo com as recomendações da Dietary Reference Intake (2011). Santa Cruz do Sul, 2012

\begin{tabular}{cccccccc}
\hline Nutriente & EAR & Média \pm DP & Mínimo & Mediana & Máximo & $\begin{array}{c}\text { Prevalência de ina- } \\
\text { dequação }\end{array}$ & CV (IC 95\%) \\
\hline Vitamina D $(\mu \mathrm{g} / \mathrm{d})$ & $10^{\mathrm{a}}$ & $3,38 \pm 4,98$ & 0,07 & 2,28 & 26,72 & $94,1 \%$ & $47,30 \%$ \\
$(1,98-4,79)$ \\
Cálcio $(\mathrm{mg} / \mathrm{d})$ & $800^{\mathrm{a}}$ & $548,55 \pm 278,02$ & 126,41 & 501,33 & 1414,29 & $86,3 \%$ & $\begin{array}{c}50,68 \% \\
(470,36-626,74)\end{array}$ \\
\hline
\end{tabular}

${ }^{a}$ Nutriente classificado com mesmo valor entre as faixas etárias 18-29 anos, 30-50 anos e 51-70 anos para ambos os sexos 


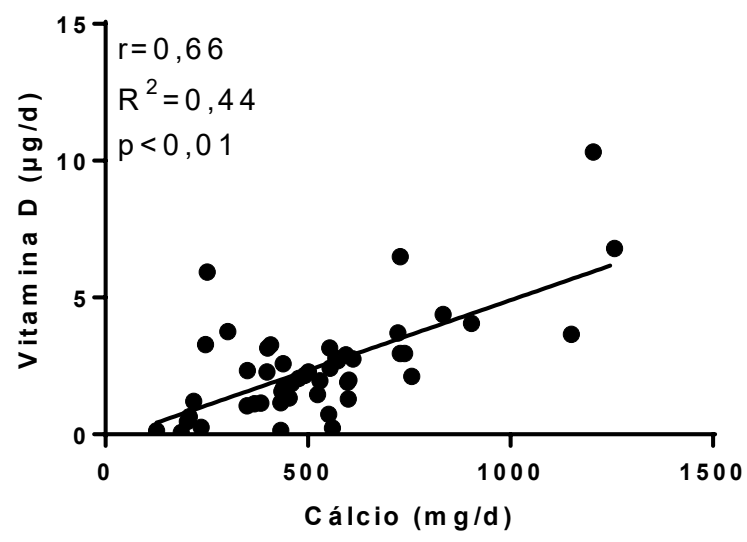

Figura 1. Associação entre vitamina D e cálcio dietéticos. r e p: coeficiente de correlação e nível de significância, respectivamente de acordo com o teste de correlação de Pearson. Santa Cruz do Sul, 2012
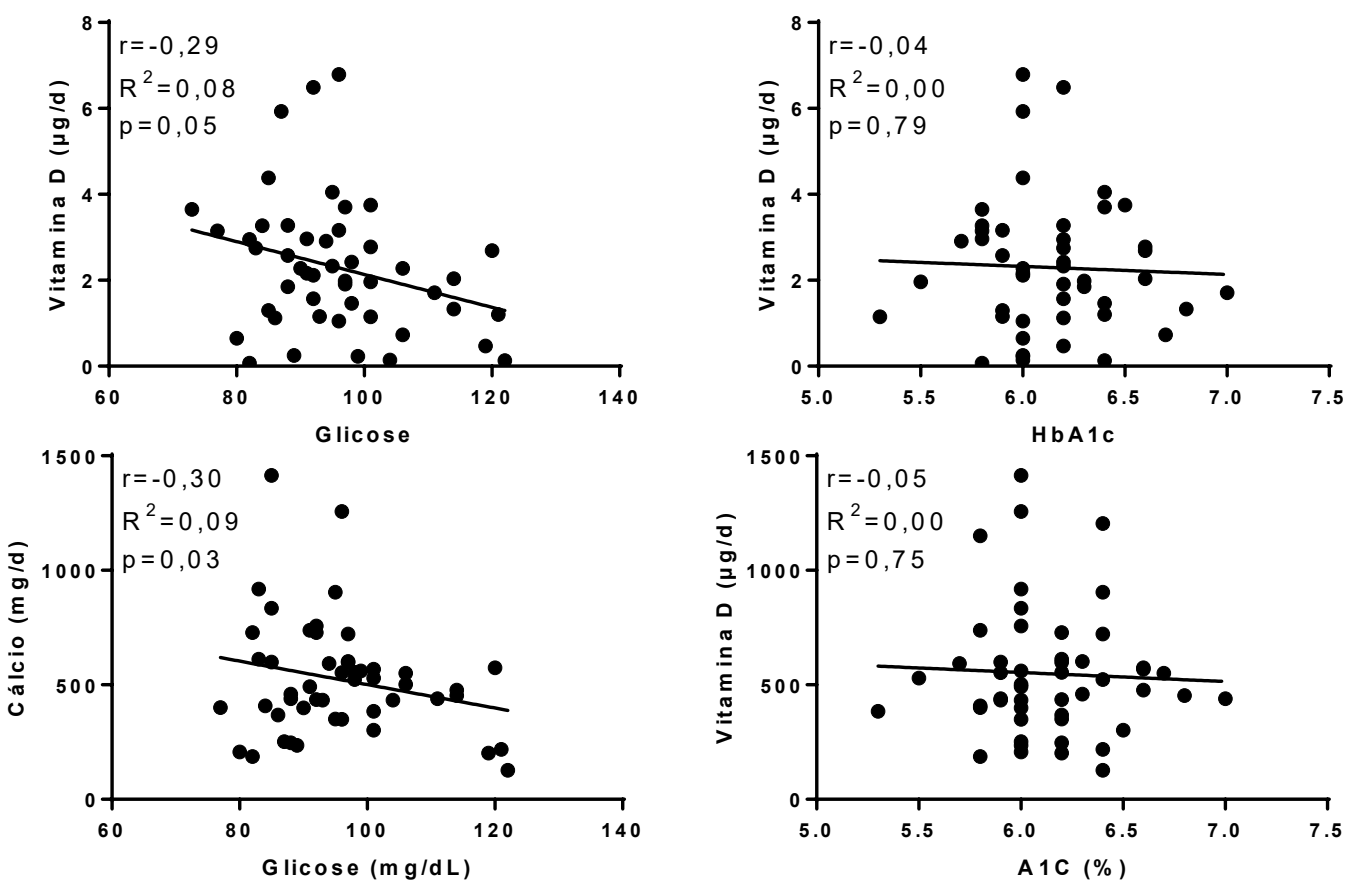

Figura 2. Associação entre vitamina D e cálcio com glicose (A, C) e hemoglobina glicada (A1C) (B, D). r e p: coeficiente de correlação e nível de significância, respectivamente de acordo com o teste de correlação de Pearson. Santa Cruz do Sul, 2012

O índice e a frequência de dano não se correlacionaram significativamente com a ingestão de cálcio $(r=0,09$ e $p=0,55 ; r=0,11$ e $p=0,47$, respectivamente $)$ nem com o consumo de vitamina $\mathrm{D}(\mathrm{r}=0,04$ e $\mathrm{p}=0,77$; $\mathrm{r}=0,05$ e $\mathrm{p}=0,75$, respectivamente) [dados não mostrados].

Quando correlacionados os danos no DNA pelo ensaio CBMN, não houve associação entre a ingestão de vitamina $\mathrm{D}$ com a frequência de micronúcleos $(\mathrm{r}=-0,09 \mathrm{e}$ $p=0,59)$, brotos nucleares $(r=-0,107$ e $p=0,535)$, nem com pontes nucleares $(\mathrm{r}=-0,06$ e $\mathrm{p}=0,71)$. Já, o consumo de cálcio mostrou correlação negativa fraca e significativa apenas com a frequência de brotos nucleares $(r=$ $0,30$ e $p=0,04)$ (Figura 3).

$\mathrm{A}$ ingestão de vitamina $\mathrm{D}$ ou cálcio não se associou com a frequência de células apoptóticas, necróticas ou com alterações nucleares $(p>0,05)$ [dados não mostrados]. 

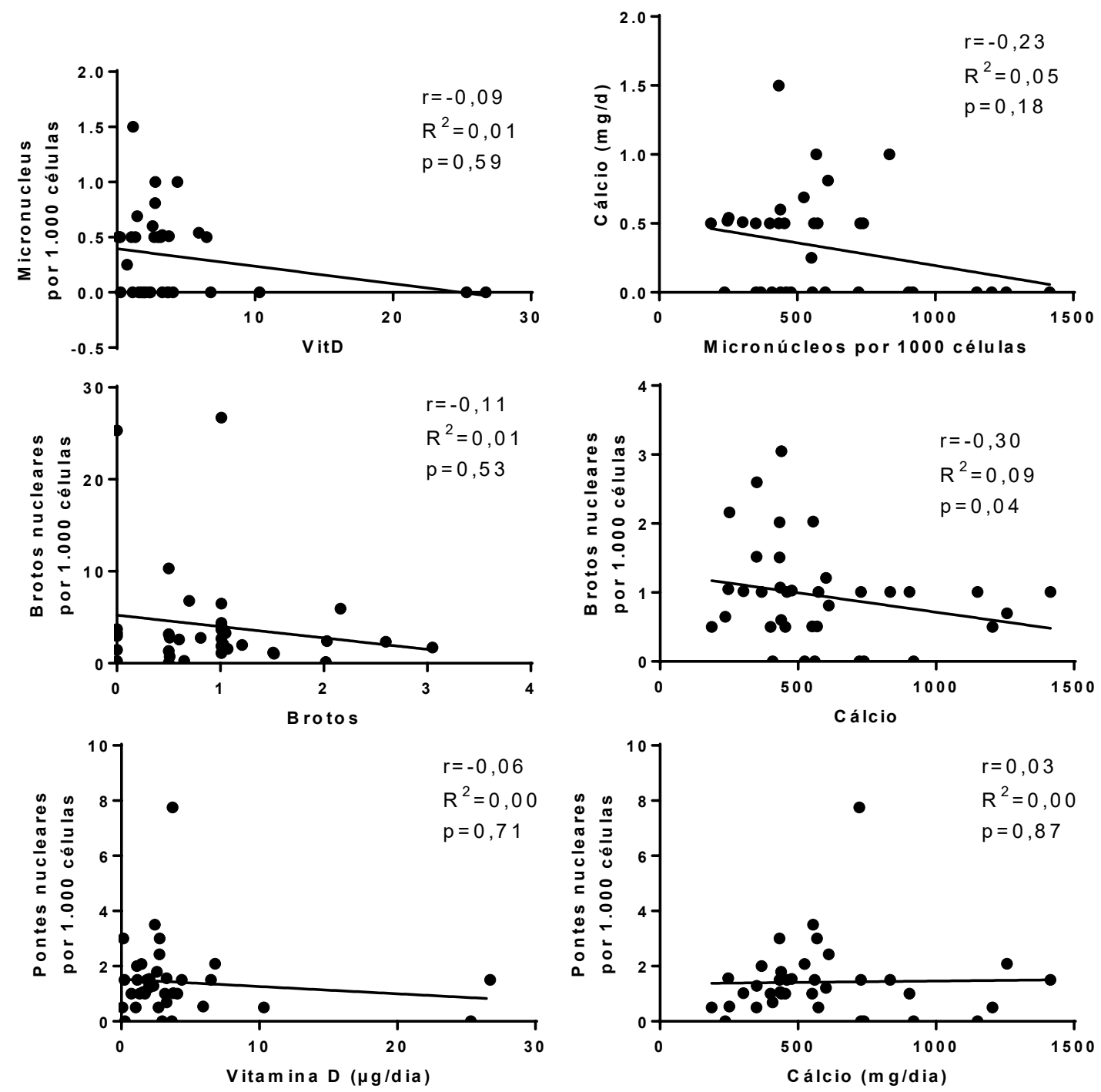

Figura 3. Associação entre vitamina D e cálcio com micronúcleos (A, B), brotos nucleares (C, D) e pontes nucleares (E, F). re p: coeficiente de correlação e nível de significância, respectivamente de acordo com o teste de correlação de Spearman. Santa Cruz do Sul, 2012.

\section{DISCUSSÃO}

O presente estudo avaliou o consumo de vitamina D e cálcio, bem como os associou com a estabilidade genômica em indivíduos pré-diabéticos, pois evidências têm sugerido que ambos os nutrientes podem influenciar no risco de desenvolvimento do DM2 ${ }^{19}$. Desta forma, mostrou que na população pré-diabética estudada houve alta prevalência de inadequação de ingestão, tanto de vitamina D (94,1\%), quanto de cálcio (86,3\%). Nossos achados corroboram com os dados apresentados pela Pesquisa de Orçamento Familiar ${ }^{20}$, no qual as prevalências de inadequação de vitamina $\mathrm{D}$ e cálcio consumidos foram altas (vitamina D: mulheres 90,71\% e homens 99,2\%; cálcio: mulheres $83,8 \%$ e homens: $99,6 \%$ ), na faixa etária de 19 a 59 anos para homens e mulheres e sem distinção para área urbana e rural.

Lucas e colaboradores ${ }^{21}$ avaliaram a ingestão de cálcio e vitamina D em uma amostra constituída apenas por mulheres adultas em diferentes faixas etárias. Esses autores verificaram que a prevalência de inadequação de vitamina D e de cálcio entre as mulheres de 30-50 anos ( $n=487$ ), foi de 78,9-80,0\% e 48,0-53,3\%, respectivamente, sendo esses percentuais inferiores aos encontrados entre as mulheres do nosso estudo que tinham a mesma faixa etária $[100,0 \%$ e 86,7\% de inadequação para vitami- 
na D e cálcio, respectivamente, dados não mostrados]. Lucas e colaboradores ${ }^{21}$ também encontraram inadequação de consumo de vitamina D e cálcio para as mulheres entre $51-60$ anos $(n=637)$ de $72,4-96,0 \%$ e $50,8-52,7 \%$, respectivamente, valores inferiores ao do nosso estudo $[100,0 \%(n=15)$ de inadequação para vitamina $\mathrm{D}$ e $86,7 \%(n=15)$ para cálcio entre as mulheres nesta fixa etária, dados não mostrados]. Ainda, os mesmos autores encontraram prevalência de inadequação de vitamina D de $70,5 \%$ e de cálcio de $41,0 \%$, entre as mulheres de 18-29 anos $(n=122)$, valores também inferiores ao do presente estudo, no qual se verificou prevalência de inadequação, entre as mulheres desta faixa etária, de 100\% $(\mathrm{n}=1)$, tanto para vitamina $\mathrm{D}$, quanto para cálcio (dados não mostrados).

Estudos observacionais têm demonstrado que a alta ingestão de vitamina $\mathrm{D}$ e/ou cálcio foram inversamente associados com concentrações de glicose e a incidência de desenvolver DM2 ${ }^{19,22,23}$, corroborando com os resultados do presente estudo. Esses achados tornam evidente que tanto a deficiência de vitamina $\mathrm{D}$, no sangue como na dieta, alteram a produção e secreção de insulina e levam a intolerância à glicose, colaborando para o risco de desenvolver DM2 ${ }^{19}$. Por outro lado, devemos ressaltar que, no presente estudo, a inadequação no consumo de vitamina D e cálcio não mostrou correlação com a concentração de hemoglobina glicada. Devemos ressaltar que não foi avaliado se estes indivíduos apresentavam níveis sanguíneos de vitamina $\mathrm{D}$ deficientes, pois tanto a exposição ao sol, bem como a sua suplementação, caso houvesse poderiam influenciar nos nossos resultados. No estudo realizado pela National Health and Nutrition Examination Survey (NHANES III) que teve como objetivo avaliar a relação entre concentrações de vitamina $\mathrm{D}$, homeostase de glicose e evolução do DM, foi observada associação inversa entre a hemoglobina glicada e as concentrações de vitamina $\mathrm{D}$, em pacientes que não tinham conhecimento de história de DM. Portanto, os mecanismos da vitamina D e hemoglobina glicada ainda não estão completamente elucidados.

A vitamina $\mathrm{D}$ tem sido mostrada por prevenir o dano no DNA, de forma direta ou indireta, induzindo a parada do ciclo celular e aumentando atividades de reparo do $\mathrm{DNA}^{24}$. Contudo, os resultados obtidos no presente estudo demonstram que o índice e a frequência de dano não se correlacionaram significativamente com o consumo de vitamina $\mathrm{D}$, nem com a ingestão de cálcio.

O ensaio de CBMN é um biomarcador de danos no DNA, amplamente utilizado para refletir mudanças dentro do genoma como consequência à exposição a agentes endógenos e exógenos ${ }^{25}$. No presente estudo a ingestão de vitamina $\mathrm{D}$ não se associou com esses tipos de danos nucleares. Diferentemente, o consumo de cálcio correlacionou-se significativamente apenas com a frequência de brotos nucleares. A carência deste mineral está relacionada à disfunção mitótica e erros na segregação cromossômica, ou seja, levando a erros na divisão celular $^{26}$, resultando em maiores chances de dano no DNA. Desta forma, nosso estudo mostrou que, conforme se aproxima das recomendações da ingestão de cálcio, há diminuição na frequência de brotos nucleares, corroborando com o estudo de Fenech ${ }^{26}$, indicando que a deficiência de cálcio pode ser um dos fatores de indução de brotos nucleares.

Ademais, a ingestão de vitamina ou cálcio também não se associou com a frequência de células apoptóticas, necróticas ou com alterações nucleares, demonstrando que o consumo inadequado de vitamina $\mathrm{D}$ e cálcio não apresentou efeito potencial citotóxico.

\section{CONCLUSÃO}

Com os resultados do presente estudo, podemos concluir que nos pacientes pré-diabéticos avaliados, ocorreu alta prevalência de inadequação do consumo de cálcio e vitamina $\mathrm{D}$ que, consequentemente, contribuiu para as alterações na glicemia de jejum, mas não na hemoglobina glicada. Além disso, ambos os nutrientes parecem pouco influenciar na instabilidade genômica, uma vez que somente o consumo de cálcio insuficiente mostrou estar relacionado na formação de danos no DNA.

A partir destes dados, foi possível obter mais informações referentes à dieta dos pré-diabéticos, uma vez que ainda há pouca informação sobre a dieta dessa população. Além disso, é essencial promover a educação nutricional salientando a importância de uma alimentação adequada e saudável de todos os nutrientes com ênfase 
na ingestão de vitamina $\mathrm{D}$ e cálcio, já no diagnóstico precoce do pré-diabetes, com o objetivo de capacitar os indivíduos a compreender melhor os hábitos alimentares, minimizando os riscos de evoluir para o diabetes, a fim de promover a normalização dos níveis glicêmicos.

\section{REFERÊNCIAS}

1. American Diabetes Association. Standards of medical care in diabetes-2014. Diabetes Care. 2014;37 (Supl 1):S14-80.

2. Milech A, Angelucci AP, Golbert A, Matheus A, Carrilho AJ, Ramalho AC. Diretrizes da sociedade brasileira de diabetes (2015-2016). São Paulo: AC Farmacêutica; 2016.

3. Souza CF, Gross JL, Gerchman F, Leitão CB. Prédiabetes: diagnóstico, avaliação de complicações crônicas e tratamento. Arq Bras Endocrinol Metab. 2012; 56(5):275-84.

4. Deus KJ. Diabetes mellitus type 2-the geneticnutrients approach. Food Nutr. 2012; 37(2):199-214.

5. Holick MF, Binkley NC, Bischoff-Ferrari HA, Gordon CM, Hanley DA, Heaney RP, et al. Evaluation, treatment, and prevention of vitamin D deficiency: an Endocrine Society clinical practice guideline. J Clin Endocrinol Metab. 2011; 96(7):1911-30.

6. Schuchu NJ, Garcia VC, Martini LA. Vitamina D e doenças endocrinometabólicas. Arq Bras Endocrinol Metab. 2009; 53(5):625-33.

7. da Silva Ferreira T, Martins Rocha T, Simas Torres Klein MR, Sanjuliani AF. Vitamin D deficiency is associated with insulin resistance independent of intracellular calcium, dietary calcium and serum levels of parathormone, calcitriol and calcium in premenopausal women. Nutr Hosp. 2015; 31(4): 1491-98.

8. Del Valle HB, Yaktine AL, Taylor CL, Ross AC, editors. Institute Of Medicine. Dietary reference intakes for calcium and vitamin D. Washington: The National Academies Press; 2011.

9. Pittas AG, Lau J, Hu FB, Dawson-Hughes B. The role of vitamin $\mathrm{D}$ and calcium in type 2 diabetes. A systematic review and meta-analysis. J Clin Endocrinol Metab. 2007; 92(6):2017-29.

10. Valko M, Leibfritz D, Moncol J, Cronin MT, Mazur $\mathrm{M}$, Telser J. Free radicals and antioxidants in normal physiological functions and human disease. Int $\mathrm{J}$ Biochem Cell Biol. 2007; 39(1):44-84.

11. Pereira CS, Molz P, Palazzo RP, de Freitas TA, Maluf SW, Horta JA, et al. DNA damage and cytotoxicity in adult subjects with prediabetes. Mutat Res. 2013; 753(2):76-81.

12. Fenech M, Crott JW. Micronuclei, nucleoplasmic bridges and nuclearbudsinduced infolic acid deficient human lymphocytes-evidence for breakage-fusionbridge cycles in the cytokinesis-block micronucleus assay. Mutat Res. 2002; 504(1):131-6.

13. Shea MK, Booth SL, Massaro JM, Jacques PF, D'Agostino Sr RB, Dawson-Hughes B, et al. Vitamin K and vitamin D status: associations with inflammatory markers in the Framingham Offspring Study. Am J Epidemiol. 2007 Nov 15;167(3):313-20.

14. Ferraz CM, Steluti J, Marchioni DM. As vitaminas e minerais relacionados à estabilidade genômica e à proteção ao câncer. Nutrire Rev Soc Bras Aliment Nutr. 2010; 35(2):181-99.

15. Fisgerg RM, Slater B, Marchioni DM, Martini LA. Inquéritos alimentares: métodos e bases científicas. Barueri: Manoli, 2005.

16. Kliemann M, Prá D, Müller LL, Hermes L, Horta JA, Reckziegel MB, et al. DNA damage in children and adolescents with cardiovascular disease risk factors. Acad Bras Ciênc. 2012; 84(3):833-40.

17. Fenech M. Cytokinesis-block micronucleus cytome assay. Nature protocols. 2007; 2(5):1084-104.

18. Hopkins W, Marshall S, Batterham A, Hanin J. Progressive statistics for studies in sports medicine and exercise science. Med Sci Sports Exerc. 2009; 41(1):3-13.

19. Rafaelli RA, Nomura PR, Figueira FD, de Freitas Santos IC, Silva LF, Venturini D. Influência da vitamina D nas doenças endocrinometabólicas. Semina: Ciên Biol Saúde. 2015; 36(Supl 1):333-48. 
20. IBGE. Pesquisa de orçamentos familiares 2008-2009: despesas, rendimentos e condições de vida. Rio de Janeiro: Instituto Brasileiro de Geografia e Estatística; 2010.

21. Lucas R, Costa L, Barros H. Ingestão de cálcio e vitamina D numa amostra urbana de mulheres Portuguesas. Arq Med. 2005; 19(1-2):07-14.

22. Mitri J, Muraru MD, Pittas AG. Vitamin D and type 2 diabetes: a systematic review. Eur J Clin Nutr.2011; 65(9):1005-15.

23. Griz LH, Bandeira F, Gabbay MA, Dib SA, Carvalho EF. Vitamin D and diabetes mellitus: an update 2013. Arq Bras Endocrinol Metabol. 2014; 58(1):1-8.

24. Nair-Shalliker V, Armstrong BK, Fenech M. Does vitamin D protect against DNA damage?. Mutat Res. 2012; 733(1):50-7.

25. Ladeira C, Pádua M, Veiga L, Viegas S, Carolino $\mathrm{E}$, Gomes MC, et al. Influence of serum levels of vitamins $\mathrm{A}, \mathrm{D}$, and $\mathrm{E}$ as well as vitamin $\mathrm{D}$ receptor polymorphisms on micronucleus frequencies and other biomarkers of genotoxicity in workers exposed to formaldehyde. J Nutrigenet Nutrigenomics. 2015; 8(4-6):205-14.

26. Fenech MF. Dietary reference values of individual micronutrients and nutriomes for genome damage prevention: current status and a road map to the future. Am J Clin Nutr. 2010; 91(5):1438S-54S.

Recebido em: 31/12/2017 Aceito em: 08/08/2018 